\title{
EL DELITO DE PERTENENCIA A UNA ORGANIZACIÓN TERRORISTA EN EL CÓDIGO PENAL ESPAÑOL
}

\author{
Manuel Cancio Meliá
}

\begin{abstract}
I. El problema; II. El delito de pertenencia y los delitos de terrorismo: 1. El concepto de organización terrorista en relación con la conducta de pertenencia; 2. Concursos: a) Infracciones instrumentales: aa) La suma automática de pertenencia e infracciones instrumentales en la jurisprudencia; bb) Pertenencia y ulteriores delitos instrumentales en procedimientos distintos; b) Conspiración (art. 579 CP) e intervención en una infracción instrumental; III. Tipicidad: 1. Titulos de pertenencia: a) Dirigentes e integrantes; b) ¿Integración inactiva?; 2. La conducta de pertenencia: a) Introducción; b) Aplicación; Epilogo.
\end{abstract}

Juan Bustos Ramirez, como es sabido, vivió en carne propia la represión de una dictadura. Represión que siempre busca la juridificación de sus actos mediante la calificación de cualquier actividad de oposición como terrorismo. Quizás ello afinó su sensibilidad para la deriva hacia la categorización, hacia la subjetivación que puede sufrir el Derecho penal -especialmente en regímenes dictatoriales-, y que tiene un punto álgido -no sólo en regímenes dictatoriales- en el ámbito del terrorismo: “...esta legislación [la antiterrorista] está basada en una relevancia total del elemento subjetivo...", hasta su completa segregación del mundo de los demás infractores: “...el terrorista no es simplemente un delincuente más, sino una especie diferente" ${ }^{\prime 2}$ ¿ $Y$ qué hace terrorista al terrorista? ¿Cómo definirlo sin caer en la mera categorización? La respuesta está en que debe ser una relación imputable con una organización terrorista la conducta que legitime la incriminación del terrorista como tal: ante todo, su conducta de pertenecer a la organización. Se trata aquí de que la dogmática defina en qué consiste la infracción, teniendo en cuenta sobre todo, ante el trasfondo de la relevancia que va alcanzando la criminalidad organizada no terrorista- que "...lo más grave de la legislación antiterrorista... es que da la imagen distorsionada de que se va a aplicar sólo y exclusivamente a los terroristas", que su problema esencial, en una palabra, es "su tendencia a socavar las bases de un Estado de Derecho democrático". Que Bustos subrayara estos riesgos que para el Derecho penal de un Estado de Derecho emanan de la legislación antiterrorista quizás justifique que se incluya en un libro editado en su memoria un estudio en el que se pretende ofrecer algunos elementos para una definición del delito de pertenencia a una organización terrorista ajena a la deriva por él advertida.

\footnotetext{
* Catedrático de Derecho Penal, Universidad Autónoma de Madrid. España.

1 Bustos Ramírez, en: Losano/Muñoz Conde, El Derecho ante la globalización y el terrorismo, p. 408; “...de un Derecho penal del hecho hay un deslizamiento subrepticio a un Derecho penal de autor", op. cit., p. 409.

2 Bustos Ramírez, op. cit., p. 408.

3 Bustos RAmírez, op. cit., pp. 406 y s.

4 Bustos Ramírez, PE, p. 394.
} 
Cancio - El delito de pertenencia a una organización terrorista...

Para ello, en primer lugar se presenta sintéticamente el problema de toda aproximación a un delito de pertenencia a una organización terrorista: su carácter límite en términos de legitimidad (infra I.). En segundo lugar, se intenta delinear la inserción de esta infracción en el contexto de los delitos de terrorismo que conoce el ordenamiento español (infra II.). Finalmente, se propone una definición de la conducta de pertenencia al hilo del tristemente rico material que ofrece la jurisprudencia española (infra III.).

\section{El problema}

Los delitos de terrorismo -al igual que el fenómeno empírico "terrorismo"-, por su significado político, constituyen un ámbito esencialmente marcado por su carácter colectivo: es la organización terrorista a la que corresponde el protagonismo en la estrategia terrorista ${ }^{5}$. Dicho de otro modo, el terrorismo es criminalidad organizada. Sin embargo, como es evidente, la organización no es reconocida como tal por el ordenamiento jurídico del Estado, que se limita a incriminar determinadas formas de relación con ella. El acoplamiento estructural decisivo entre la organización empírica y el individuo que es penado por apoyarla está en el delito que consiste en formar parte de ella, en ser la carne de la organización: el delito de pertenencia a una organización terrorista.

Es ésta una infracción que plantea serias dificultades a la teoría del Derecho penal, como antes se decía: desde el punto de vista de los delitos normales, que aprehenden la realización de una conducta concreta que lesiona o pone en peligro un concreto bien jurídico, el delito de pertenencia a una organización criminal (= "asociación ilícita"), y, en España, sobre todo -por su amplia presencia en la praxis de los tribunales, a diferencia (hasta ahora) de la asociación ilícita ordinaria- de pertenencia a una organización terrorista, incluye formas de mera protoparticipación o pre-preparación. Es necesario describir la conducta que se pena para evitar que se conciba como una mera adhesión, como una categorización formal como uno de ellos.

La regulación del delito de pertenencia o integración en una organización terrorista destaca por su voluntad manifiesta -dentro de lo que se puede llamar ideología de la normalidad ${ }^{6}$ - de tratar a la organización terrorista como a una asociación ilícita ordinaria, si bien no igual a las demás ${ }^{7}-$ sino más grave ${ }^{8}$, como muestra la

\footnotetext{
5 Cfr. sólo la sintética y sustanciosa argumentación en LuTZ/LuTZ, Global Terrorism, p. 11: “For political violence to be terrorism there must be an identificable organization. An individual is unable to carry out the actions, reach the target audience, and present the political demands that are necessary to end the violence." Sobre el llamado "terrorismo individual" en el art. 577 del Código penal español, vid. próximamente CANCIO MELIÁ, Los delitos de terrorismo: estructura típica e injusto (en prensa para editorial Reus, Madrid), $₫ 3 \mathrm{~V}$.

${ }^{6}$ CANCIO Meliá, JpD 44 (2002), pp. 19 y ss.; IDEM, Los delitos de terrorismo, \2. III. B. 5. b)

7 Esta decisión del legislador es sometida a crítica por PORTILLA CONTRERAS (en: COBO DEL Rosal, Curso PE II, p. 721), para quien la penalidad debería ser idéntica a la del art. $515.1^{\circ} \mathrm{CP}$ : "se
} 
penalidad notablemente agravada contemplada en el art. 516 en relación con el art. $517 \mathrm{CP}^{9}-$, no necesitada de un tratamiento especial escenificado en una ubicación sistemática distinta de las demás asociaciones ilícitas.

Sin embargo, en contraste con ello, dentro de los análisis en torno a la actual evolución de la política criminal, también ocupa una posición central esta infracción como muestra paradigmática del llamado "Derecho penal" del enemigo ${ }^{10}$. Como puede sostenerse en relación con el injusto de los delitos de organización con carácter general ${ }^{11}$, el punto de partida aquí adoptado no atribuye in toto y desde el principio este tipo de figuras al ámbito de lo no legitimable (al menos, como Derecho penal ${ }^{12}$. Esto colocaría al intérprete, por lo demás, de un modo peculiarmente drástico entre la espada del reconocimiento de tal Derecho como segmento legítimo y la pared de su combate en el plano de la crítica políticocriminal externa ${ }^{13}$. Por el contrario, aquí se intentará encontrar el tertium de una interpretación que permita un entendimiento legítimo y dogmáticamente operativo de esta infracción, con base en la especificidad en el injusto de los delitos de terrorismo. Esto, como es natural, se hará dentro de los límites que tiene un análisis dogmático-jurídico: hay decisiones del legislador que no son susceptibles de ser integradas en el sistema por el intérprete, como se verá en más de una ocasión. En todo caso, como actitud hermenéutica -y como debe hacerse en el análisis de las dimensiones de injusto de los delitos de organización en general- parece muy

vulnera, por tanto, el principio de igualdad por el que todas las asociaciones con fines delictivos deberían entrar en el apartado $1^{\circ}$ del art. 515"; sin embargo, no se percibe por qué no debería el legislador distinguir entre organizaciones que presenten mayor o menor grado de relevancia a efectos de injusto; sobre las diferencias en términos de injusto entre criminalidad organizada común y terrorismo, vid. sólo CANCIO MELIÁ, FS Jakobs, pp. 48 y ss., 50.

8 Así, se habla de que se trata de una "forma específica y agravada" del delito común de asociación ilícita SAN (secc. $2^{\mathrm{a}}$ ) 31.3.2006, o de "un subtipo agravado del delito de asociación ilícita" (SAN 6/2007 (secc. 1 $\left.1^{\mathrm{a}}\right)$ 7.2.2007).

9 También se produce una agravación más que notable en la pena en comparación con la que se preveía en el anterior art. $174.3^{\circ}$ CP TR 1973 (prisión mayor en su grado máximo y prisión mayor): se pasa a una pena, en el caso de los sujetos en la dirección, que está en el ámbito de la que corresponde al homicidio doloso, por ejemplo (ocho a catorce años frente diez a quince), y en el de los meros integrantes, en el de la violación, por ejemplo (seis a doce años, idéntica).

10 Vid. sólo JAKOBS, Estudios de Derecho Judicial 20, p. 138; sobre el concepto cfr. sólo JAKOBS, ZStW 97 (1985), pp. 753 y ss.; IDEM, HRRS 3/2004; IDEM, Staatliche Strafe, 40 y ss.; IDEM, en: CAncio Meliá/GómeZ-Jara DíEZ, Derecho penal del enemigo vol. 2, pp. 93 y ss. A favor de la potencia analítica del concepto, en contra de su compatibilidad con el Derecho penal de un Estado de Derecho vid. CANCIO MELIÁ, ZStW 117 (2005), pp. 267 y ss.; IDEM, en: JAKOBS/CANCIO MELIÁ, Derecho penal del enemigo ${ }^{2}$, pp. 85 y ss.

11 CANCIO MELIÁ, FS Jakobs, pp. 27 y ss.

12 Cfr. la posición de JAKOBS (por ejemplo, en ZStW 117 [2005], pp. 839 y ss.), quien en todo su trabajo parece dar por supuesto que la mera existencia de un delito de organización identifica un campo de Derecho penal del enemigo; sobre el análisis más matizado del propio JAKOBS en su decisivo estudio sobre la "criminalización en el estadio previo", publicado veinte años antes, vid. CANCIO MELIÁ, FS Jakobs, pp. 38 y ss.

13 Como dice Silva SÁNCHEZ (LH Ruiz Antón, p. 1074), "no es seguro que la alternativa sea real". 
Cancio - El delito de pertenencia a una organización terrorista...

conveniente tener presente la argumentación, desarrollada en la doctrina española sobre todo por Sánchez García de Paz , en torno a la idea de que la cuestión de los delitos de pertenencia a una organización constituye un problema que materialmente es de carácter general, un "problema material de imputación, y no un problema de mera tipificación formal" $"$.

\section{El delito de pertenencia y los delitos de terrorismo}

\section{El concepto de organización terrorista en relación con la conducta de pertenencia}

Como antes se indicaba, el elemento común de todas las infracciones de terrorismo (sean periféricas: las de colaboración externa, instrumentales: los delitos de estragos, asesinatos, etc., cometidos en los atentados, o estructurales: las de pertenencia) es la existencia de una organización terrorista. Por ello, todo análisis dogmático en este campo debe incorporar como elemento central la definición de lo que es una organización terrorista. Si se busca un punto de partida para la interpretación operativa de las características de la estructura "organización terrorista", está claro que el concepto central en el Derecho penal positivo español es el de asociación, especialmente, en lo que se refiere a su delimitación frente al de la conspiración. En este sentido, como ha señalado en la doctrina española sobre todo García-Pablos de Molina $^{16}$, a los efectos del precepto que aquí interesa ha de utilizarse un concepto funcional de asociación en el sentido de "organización": "una estructura que se proyecta más allá de la comisión de unos hechos concretos"17. Otros elementos como el número de integrantes, la cuantificación de la permanencia en el tiempo, etc., son secundarios frente a la exigencia de que se trate de una estructura organizada en la que quepa distinguir distintas funciones.

El precepto del art. 516 CP recoge en el CP 1995 en artículo aparte las infracciones de pertenencia a banda armada u organización o grupo terrorista (antes contempladas en el art. $174.3^{\circ} \mathrm{CP}$ TR 1973). Como es natural desde la perspectiva interna de toda la regulación de las infracciones de terrorismo, las penas son superiores a las previstas en el artículo para la pertenencia a alguna de las otras asociaciones ilícitas, en atención al triple fundamento agravatorio de la especial peligrosidad derivada de la existencia de una organización, los medios específicos de actuación utilizados y la proyección estratégica que dan lugar a la noción de terrorismo, es decir, a la especificidad en el tratamiento jurídico-penal de las actividades de miembros de organizaciones terroristas. En este sentido, como cabe proponer en la

\footnotetext{
14 Fundamental a este respecto SCHROEDER, Die Straftaten gegen das Strafrecht, pp. 9 y ss., 11, 21; vid. también en esta línea LANGER-STEIN, Legitimation und Interpretation, p. 165; SÁNCHEZ GARCÍA DE PAZ, LH Barbero Santos, pp. 647, 673 y ss.; SilVA SÁNCHEZ, LH Ruiz Antón, p. 1074.

15 Silva SÁNCHEZ, LH Ruiz Antón, p. 1074.

16 ComLP II, pp. 116 y ss.

17 Terradillos Basoco, CPCom, p. 407.
} 
determinación del concepto típico de terrorismo ${ }^{18}$, el específico injusto viene determinado tanto por la especial peligrosidad que deriva del multiplicador que es la estructura, como del significado radicalmente ilegítimo de la utilización de los medios específicos y de la puesta en cuestión de los procedimientos básicos de actuación política en el ordenamiento.

Cabe pensar en diversos supuestos concretos que pueden indicar que, efectivamente, no sólo es una especial peligrosidad -como es el caso en las demás asociaciones ilícitas- lo que genera el específico injusto de las organizaciones terroristas: así, por ejemplo, puede afirmarse que en el momento actual los GRAPO ${ }^{19}$ se encuentran "en vías de extinción" embargo, difícilmente se dudará que (aún) se trata de una organización terrorista, teniendo en cuenta la persistencia de la autodefinición de sus componentes residuales como activistas (políticos) de su organización ${ }^{21}$. Parece claro, entonces, que la superior pena que corresponde en el art. $516.2^{\circ} \mathrm{CP}$ a la organización terrorista -aún en los casos en los que su peligrosidad es notablemente inferior a las de otras organizaciones criminales del art. $517 \mathrm{CP}$ - sólo se explica (también) con base en la especial proyección estratégica -los fines políticos de la organización- que es propia de la organización terrorista.

Es en tal organización específicamente terrorista en la que se integra el sujeto activo -llegándose a calificar esta circunstancia como "sustrato primario" del delito de integración ${ }^{22}$-, realizando una conducta de pertenencia (vid. infra III.) adaptada a las características de esta clase de organización.

\section{Concursos}

¿Qué relación debe mantener esa conducta -aún por definir- de ser miembro, de pertenecer a la organización terrorista con los demás delitos de terrorismo?

\section{a) Infracciones instrumentales}

\footnotetext{
18 Vid. CANCIO MELIÁ, LH Gimbernat, t. II, pp. 1879 y ss.

19 "Grupos Revolucionarios Armados Primero de Octubre"; vid. el profundo estudio monográfico sobre esta organización presentado recientemente por ROLDÁN BARBERO, Los GRAPO, passim; sobre otras organizaciones terroristas españolas que han pasado por similares circunstancias en el pasado, vid. la sucinta información en AvILÉs GÓMEZ, Criminalidad organizada, pp. 428 y ss.

20 AviLÉs Gómez, Criminalidad organizada, p. 427. Cfr. sólo el relato en "El GRAPO mata para sobrevivir", en: diario El País, 26.2.2006; vid. los datos referidos a los últimos años en la actividad de esta organización en: www.institutodevictimologia.com/Grafic07.pdf y las perspectivas de futuro esbozadas por ROLDÁN BARBERO, Los GRAPO, pp. 165 y ss., 168 y ss.

21 Que se concibe a sí misma como brazo armado de un "partido político", el PCE-r (Partido Comunista de España - reconstituido); vid. sólo la información en ROLDÁN BARBERO, Los GRAPO, pp. 1 y ss., 21 y ss.; http://es.wikipedia.org/wiki/GRAPO.

22 STS 119/2007 (16.2.2007).
} 
Cancio - El delito de pertenencia a una organización terrorista...

\section{aa) La suma automática de pertenencia e infracciones instrumentales en la jurisprudencia}

En lo que se refiere a la aplicación conjunta de la figura de la pertenencia a la organización terrorista y de alguna de las infracciones instrumentales cometidas en el marco de las actividades de la misma, existe una persistente discrepancia entre doctrina y algunos segmentos de la jurisprudencia: puesto que la conexión con la organización -pertenencia, actuar al servicio o colaborando- es elemento esencial del tipo de los delitos de terrorismo en sentido estricto ${ }^{23}$, parece elemental que concurre un supuesto de bis in idem si se aplica el delito de pertenencia a banda armada u organización terrorista además de otra infracción de terrorismo ${ }^{24}$, sin admitir que aquí se trata de un caso de concurrencia del principio de consunción del art. $83^{\mathrm{a}} \mathrm{CP}$. En este sentido, debería aplicarse exclusivamente el delito instrumental, que comprende en su tipo, como acaba de decirse, la conexión con la organización, incluyendo también los supuestos en los que esa conexión consiste en la integración en la organización ("perteneciendo"). A esta consideración, sin embargo, alguna jurisprudencia contesta con una petitio principii, rechazando la concurrencia del bis in idem y afirmando que lo que procede es el concurso real:

“...lo que se está suscitando es el desconocimiento por la Audiencia del principio «non bis in idem». Sin embargo no hay tal y se trata de dos hechos perfectamente diferenciados cuya relación no es otra que la de un concurso real. El delito de integración o pertenencia a bandas armadas y a organizaciones terroristas (artículo 516.2 en relación con el 515.2 CP) por el que han sido castigados es un delito de carácter permanente que subsistirá siempre que la voluntad del autor consienta dicha adscripción, sin que por otra parte el tipo referido, a diferencia del caso del artículo 517.2, exija una actividad determinada a los mismos. Por otra parte, el propio artículo 574 prevé la comisión de otras infracciones por las personas pertenecientes a las organizaciones referidas, exasperando la pena aplicable a las mismas, siempre y cuando se cometan con alguna de las finalidades expresadas en el artículo $571 \mathrm{CP}$. De ello se sigue que las acciones concretas realizadas por los miembros de la banda constitutivas de una infracción penal autónoma son independientes del delito de pertenencia o integración, pues se trata de sustratos de becho diferentes.".

Parece claro que esta afirmación -que se trata de dos hechos distintos- sólo es posible a través de una manipulación de la base fáctica de la noción de delito

23 Vid. CANCIO Meliá, Los delitos de terrorismo, \ 3 V., respecto del delito incriminado en el art. 577 CP.

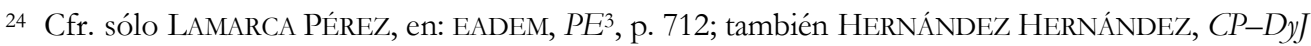

III, p. 4902, con ulteriores referencias; a favor de apreciar concurso de delitos, en cambio MORAL DE LA RosA, Terrorismo, pp. 188 y ss.

25 SAN 12/2003 (secc. 4a) 1.4.2003, sin cursiva en el original; explícita en este sentido también la STS 14.10.1987. 
permanente. Partiendo, como aquí se hace -en consonancia con el entendimiento del bien jurídico de las infracciones en cuestión-, de que la pertenencia a la organización terrorista supone una infracción no sólo de orientación policialfáctica, sino también, en el plano del significado político, de negación de los elementos fundamentales de la actuación colectiva ${ }^{26}$, parece imposible desconocer que precisamente esto es lo que está también en la base de las infracciones instrumentales. Sólo así puede explicarse la agravación de la pena respecto de las infracciones comunes: los delitos de terrorismo son aportaciones condensadas a título de colaboración o pertenencia, existen como tales por su significación colectivo-terrorista, por lo que no es posible penar este montante de injusto una segunda vez a través de figura de la pertenencia.

En todo caso, en síntesis, hablar aquí de dos supuestos de hecho distintos carece de sentido, y se castiga al sujeto dos veces por el mismo desvalor. Ello sólo se explica con base en la introducción de una protuberancia punitiva: se categoriza al sujeto como enemigo, y ya no es decisivo qué ha hecho, sino quién es.

\section{bb) Pertenencia y ulteriores delitos instrumentales en procedimientos distintos}

La cuestión se presenta de modo distinto, como es obvio, cuando el sujeto ha sido ya enjuiciado y condenado por integración en organización terrorista y es procesado con posterioridad por alguno de los delitos instrumentales. En tal caso, podrá producirse una condena por el ulterior delito instrumental, detrayendo de la pena correspondiente aquel segmento que ya ha sido penado en el procedimiento anterior a través de la pena impuesta por el delito de integración.

\section{b) Conspiración (art. 579 CP) e intervención en una infracción instrumental}

Más allá de la aplicación de un concurso de delitos entre integración y delitos instrumentales, la delimitación de conductas ejecutivas y actos preparatorios (punibles) adquiere especial dificultad cuando se trata de definir los actos preparatorios respecto de infracciones - como muchas de las de terrorismo- cuyas conductas típicas constituyen con frecuencia a su vez materialmente supuestos de preparación de futuros delitos. Queda claro, entonces, que se presenta un problema de delimitación específico de la conducta de pertenencia típica respecto de los actos preparatorios incriminados en el art. 579 CP: ¿cuándo debe calificarse la conducta como comportamiento de pertenencia, cuándo como conspiración para un determinado delito instrumental?

Parece claro que la respuesta está en que en un sistema como el español por contraposición a un sistema en el cual el eje no sea la pertenencia a una organización criminal, sino un catálogo de supuestos de conspiración, como sucede en el círculo jurídico anglosajón-, la conspiración requiere de una

${ }^{26}$ CANCIO MELIÁ, FS Jakobs, pp. 27 y ss.; IDEM, LH Gimbernat, pp. 1879 y ss. 
Cancio - El delito de pertenencia a una organización terrorista...

concreción de los planes hacia un hecho determinado: por un lado estaría la contribución a la estructura general del colectivo, a sus planes generales (pertenencia), por otro, un proyecto delictivo concreto (conspiración):

"No puede inferirse que existiera una conspiración para atentar contra un objetivo concreto en España. El delito de conspiración para delinquir requiere que la conspiración sea sobre un objetivo cierto, y que la misma contemple acciones concretas a perpetrar. El genérico tratamiento de la fijación de objetivos sobre los que verificar inconcretos y futuros actos terroristas, constituye actividad que se absorbe en el delito de integración en banda terrorista, y, la misma, pasa a constituir indicio sobre la integración en organización terrorista..., siendo punible sólo como acto preparatorio independiente la conspiración efectiva en la que se detallase la acción a seguir, el objetivo concreto contra el que atentar, y en la que se cuenta con planos, información de colaboradores relativa a horarios, personas, vías de entrada y de salida en el pretendido objetivo etc., esto es, con una serie de elementos objetivables que diferencien la efectiva conspiración con serio propósito de atentar, de la mera maquinación." 27

Con el mismo criterio deberán tratarse, como es lógico, aquellos supuestos en los que es dudoso si nos encontramos aún en el ámbito de una mera conducta de integración en la organización o si, por el contrario, la conducta de pertenencia (vid. a continuación III.) se ha concretado ya en la comisión de un delito instrumental (debiendo quedar consumida, como se acaba de exponer supra a), entonces, la integración en la infracción instrumental): se trata de determinar si la conexión es sólo con la organización, sosteniendo su funcionamiento en cierto sentido en abstracto, o si, por el contrario, se ha producido la concreción de su aportación en un proyecto específico de actuación de la organización.

Así, por ejemplo, si un sujeto forma parte de un comando dedicado a la comisión de atentados, pero su función dentro de éste no es la de ejecutar los homicidios, sino cubrir la retirada de los miembros encargados de éstos, ocultándolos en su vivienda -no de modo puntual, sino como asignación de una función dentro de la estructura del comando-, ya no habrá una mera conducta de integración en la organización, sino una de participación (complicidad o cooperación necesaria, según las circunstancias del hecho) en la ejecución de los concretos homicidios o asesinatos terroristas cometidos en reparto de funciones por el comando en su conjunto.

27 SAN 6/2007 (secc. 1 1) 7.2.2007. 


\section{Tipicidad}

\section{Títulos de pertenencia}

\section{a) Dirigentes e integrantes}

En la regulación actual por el CP 1995 se sigue distinguiendo en el art. 516 -como en la disposición antecesora- entre "promotores", "directores" de las bandas u organizaciones, "dirigentes" de cualquiera de sus grupos (número primero) y los meros "integrantes" de estos colectivos (número segundo). La tipificación penal, por lo tanto, distingue dos niveles de pertenencia: los cuadros de la organización y los meros militantes.

En el número primero se mantiene, sin razón material alguna, como se verá, para el miembro de una organización terrorista una terminología distinta a la prevista para los sujetos que dirijan las demás asociaciones ilícitas ${ }^{28}$. Sin embargo, no parece haber dudas de que el texto se refiere a la misma situación tanto en este artículo como en el siguiente ${ }^{29}$ : a aquellos sujetos que dentro del reparto de funciones interno de la organización ostenten el control sobre las actividades de la misma.

Especialmente interesante resulta a este respecto la STS 28.10 .1997 (caso Filesa), que, aunque referida a la pertenencia a una asociación ilícita del art. 515.1 en relación con el art. $517 \mathrm{CP}$, ofrece algunos elementos directamente aplicables a las organizaciones terroristas, como puede observarse: "Los fundadores [= "promotores"], como su nombre indica, son los que iniciaron la asociación, son los creadores de la misma. Los directores [= "dirigentes de grupo"] suponen una participación más activa porque tal función implica a los que gobiernan, rigen u ordenan la actuación de aquélla. Por último, los presidentes [ $=$ "directores" de la organización] son los que desempeñan la plaza de principal o superior de la misma..."

\section{b) ¿Integración inactiva?}

Una diferencia de posible relevancia material en la nueva redacción del tipo en el CP 1995 puede apreciarse en lo que se refiere a los sujetos de menor rango integrantes de las respectivas asociaciones. Mientras que el art. $516 \mathrm{CP}$ incrimina la conducta de los meros "integrantes", el artículo 517 CP parece exigir, tras una primera lectura, un grado de implicación superior al hablar de los miembros "activos" ${ }^{\text {"30 }}$. La infracción

\footnotetext{
28 Pues el art. 517 CP 1995 habla de "fundadores, presidentes y directores"; el único cambio frente a la regulación anterior, que hace aún más incomprensible que no se haya unificado la terminología, es el de hacer referencia en el presente artículo a los "directores" en vez de "directivos", como lo hacía el antiguo Código.

29 Así, por ejemplo, ya Terradillos Basoco, CPCom, p. 407.

30 Sobre el origen de la introducción de esta alternativa de la integración tout court vid. sólo Terradillos Basoco, Terrorismo y Derecho, pp. 81 y s.
} 
Cancio - El delito de pertenencia a una organización terrorista...

del "integrante" del delito de pertenencia a organización terrorista queda entonces aparentemente configurada como delito de mera actividad en un sentido extremo, que no exige colaboración efectiva del sujeto ${ }^{31}$ más allá de su integración (formal) en el colectivo:

"...el tipo penal de pertenencia a banda armada es un delito formal o de simple actividad que produce una absoluta desconexión estructural entre el delito asociativo y los que puedan cometerse formando parte del grupo organizado, que serán incriminados particularmente en cada caso concreto. Basta cualquier acto de cooperación para la consumación de delito sin que, dada la autonomía de la figura asociativa, se requiera que los actos de cooperación se perfilen como integrantes de las infracciones criminales cuya realización constituye el objeto del grupo." ${ }^{32}$

En este sentido, entonces, podría estimarse que se castiga aquí la "pertenencia inactiva", en contraposición con la pertenencia activa ${ }^{33}$.

Sin embargo, este entendimiento del delito de pertenencia a organización terrorista es erróneo: no se mantiene dentro de los límites que la estructura típica de las infracciones de terrorismo señalan con claridad al intérprete ${ }^{34}$. La integración no puede ser de carácter "ideal" precisamente desde la perspectiva de un modelo que tenga en cuenta la dimensión de los medios típicos (terrorismo, con todas sus implicaciones operativas: clandestinidad, defensa frente a los servicios de inteligencia del Estado) fijados en el ordenamiento jurídico español como elemento definitorio, esta definición de terrorismo halla su correspondencia en la clase de organización que el tipo aprehende. Se trata de organizaciones cuyas estructuras requieren de muchas aportaciones escalonadas hasta alcanzar la pertenencia. El

31 Posiblemente constitutiva de un delito autónomo de colaboración, art. $576 \mathrm{CP}$, vid. CANCIO MELIÁ, Los delitos de terrorismo, \3. IV.

32 STS 15.4.1993; a pesar de ello, de modo incoherente, se ha estimado en algún caso la concurrencia de una tentativa (STS 30.9.1993).

33 Vid. sólo Terradillos Basoco, Terrorismo y Derecho, pp. 83 y s.; POrTILla CONTRERAs, en: COBO Del Rosal, Curso PE II, p. 721; MANJón-CABEZA Olmedo, en: LH Ruiz Antón, p. 557; para SILVA SÁNCHEZ, esto sería consecuencia del "modelo de transferencia" (en cuanto al injusto de la organización criminal: un modelo en el que existe un injusto colectivo), mientras que "el modelo de intervención propia" (en términos de injusto: el modelo [exclusivamente] peligrosista) conduciría a la impunidad, LH Ruiz Antón, pp. 1088 y s.; vid. la crítica a la posición de SiLva SÁNCHEZ en CANCIO MELIÁ, FS Jakobs, pp. 41 y s., 45 con nota 88.

34 En Alemania - respecto del delito común (asociación ilícita) del $\int 129$ StGB, cuya formulación coincide en esto con el precepto del $\int 129$ a StGB, referido al terrorismo- es opinión común que la conducta de pertenencia implica que el sujeto se integra en la organización y subordina a la voluntad de la organización, pero, además, lo hace "desplegando una actividad-aunque ésta se bubiera limitado basta ese momento a un solo acto- de fomento de los fines criminales de la asociación", no bastando una pertenencia meramente formal (vid. sólo KINDHÄUSER, LPK-StGB2, \129 n.m. 18 y s., con ulteriores referencias); lo cierto es que la fórmula empleada en el texto legal alemán ("Beteiligter") sugiere que haya una Beteligung, una "intervención" que -tanto en alemán como en castellano- ya en el lenguaje común se asocia a una actividad positiva, no a un estatus formal. 
acceso al círculo interno implica la realización de aportaciones a la estructura de la organización consistentes en infracción criminal. Dicho en una frase, en la praxis de las organizaciones criminales no puede haber pertenencia sin actividad, y, por lo tanto, no debe ser construida artificialmente por la interpretación del precepto para eludir dificultades de prueba.

Esta afirmación necesita de una concreción directa en los supuestos a los que resulta aplicable la noción de pertenencia; en este sentido, es necesario concretar los supuestos de comportamientos abarcados por el tipo.

\section{La conducta de pertenencia}

\section{a) Introducción}

Con lo dicho aún nada se ha avanzado en la cuestión de qué es lo que supone materialmente la conducta típica incriminada en el número segundo del art. 516 CP. Sin embargo, es imprescindible que por vía de interpretación se halle una definición de la conducta típica; con independencia de la redacción típica concreta -que recurre a diversos sustantivos para determinar distintos títulos de pertenencia-, no se incrimina un estatus personal, sino un acto, un comportamiento de integración en la organización. Sin embargo, ¿cuál es el contenido típico de la integración, de la mera pertenencia, en la infracción que aquí interesa? ${ }^{35}$; también aquí habrá que definir alguna conducta que dé lugar a la la comisión del delito ${ }^{36}$. La cuestión es cómo debe determinarse esa integración o pertenencia.

Un primer interrogante decisivo en este ámbito no pertenece, en puridad de términos, a la interpretación material del alcance típico: sea cual sea el contenido que haya que dar a la noción de integración, hay que plantear la cuestión de cuáles son los elementos fácticos que autorizan a afirmar que un sujeto es integrante de una organización terrorista, cómo se produce, en definitiva, la prueba. Como es evidente, en el caso de una actividad por definición clandestina, en pocas ocasiones se podrán presentar a juicio pruebas directas del "acto formal" de la integración en la organización terrorista o llevar la "hoja de servicio" en la que se haga recuento de las "aportaciones" del miembro. Entonces, la prueba de la condición de miembro de la

\footnotetext{
35 Dice Portilla Contreras (en: Cobo del Rosal, Curso PE II, p. 721) que la “omisión en este precepto [art. $516 \mathrm{CP}$ ] de referencia alguna sobre el carácter activo o no de la intervención parece querer ampliar la sanción a los 'simpatizantes' que sólo contribuyen de forma testimonial...". Desde el punto de vista aquí adoptado, si ésta era o es la intención del legislador -un factor que, como es sabido, no puede ser el único decisivo en la interpretación de una norma-, debe ser corregida mediante una interpretación sistemática; en esta misma línea se manifestaba ya respecto de la punición de las asociaciones ilícitas no terroristas en la PANCP CARBONELL MATEU (DJ $37 / 40$ [1983] vol. 2, p. 1303), reclamando la supresión de la punición de los meros "afiliados".

36 Para la definición material del umbral de tipicidad adquiere relevancia también, como es obvio, la determinación de la tipicidad del delito de colaboración con organización terrorista; vid. sólo CANCIO MELIÁ, Los delitos de terrorismo, $\int 3$ IV.
} 
Cancio - El delito de pertenencia a una organización terrorista...

organización ${ }^{37}$ deberá producirse mediante una prueba de indicios. Por lo tanto, habrá que proceder a elaborar una especie de catálogo de situaciones fácticas que deben entenderse como indicativas -que permiten una inferencia racional- de la concurrencia de la integración en la organización terrorista. Esta es una cuestión relativa a la prueba de un elemento objetivo, de la integración (objetiva) en una organización (objetivamente) terorista: no es decisivo, como parece claro, que un sujeto desee con todas sus fuerzas ser aceptado en las filas de una organización, si ésta finalmente no lo encuentra conveniente y no lo acepta como miembro, quizás tras un perído de prueba. No ha tenido, desde luego, la relación orgánica con la organización que puede ser denominada condición de miembro.

\section{b) Aplicación}

En todo caso, como se mostrará a continuación, se aprecia en la jurisprudencia -a través de una determinada práctica de prueba en cada caso- un criterio más que vacilante, que conduce, en ocasiones, a penar de modo distinto supuestos de hecho plenamente equivalentes en sentencias dictadas en un espacio de tiempo reducido.

1. Una definición general de la pertenencia a la organización debe incluir una descripción de la actividad típica, sin la cual no se alcanza el compromiso personal del integrante que da fuerza y autonomía a la organización como realidad emergente, sin la cual no puede existir la estructura interna del colectivo ${ }^{38}$ :

“...la integración en organización terrorista ha venido a ser jurisdiccionalmente establecida cuando quedan acreditadas realizaciones de actos directos definidos como fines por el grupo, siempre que también comparezcan los rasgos de permanencia, estabilidad y sometimiento a los dictados de la organización." 39

En otros pronunciamientos, en cambio, parece orientarse la definición más a la mera adhesión:

"Como señala la jurisprudencia de esta Sala, el tipo penal de pertenencia a banda armada es un delito formal o de simple actividad que produce una absoluta desconexión estructural entre el delito asociativo y los que puedan cometerse formando parte del grupo organizado, que serán incriminados particularmente en cada caso concreto. Basta cualquier acto de cooperación para la consumación de delito sin que, dada la autonomía de la figura asociativa, se requiera que los actos de cooperación se perfilen como

\footnotetext{
37 Tanto en el plano objetivo, de la inclusión material del sujeto (desde la perspectiva de la organización), como en el subjetivo (conocimiento de su integración en una organización terrorista).

38 Vid. la definición de "organización terrorista" propuesta en CANCIO MELIÁ, Los delitos de terrorismo, \2. III. B. 3.

39 SAN 28/2000 (secc. $4^{a}$ ) 20.10.2000, sin cursiva en el original.
} 
integrantes de las infracciones criminales cuya realización constituye el objeto del grupo" 40 ; “...el acento jurídico-penal debe residenciarse en la pertenencia a esa organización, estructurada, jerarquizada, movida por fines

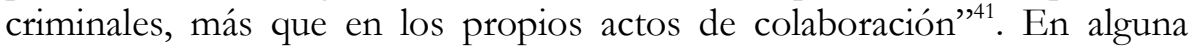
ocasión incluso se llega a considerar suficiente la mera manifestación de la adhesión, el ingreso formal: "Nuestra jurisprudencia reiterada es clara, al entender que la condición de miembro de la organización se adquiere tras el acto de admisión de la persona en cuestión en las filas de la organización terrorista" ${ }^{, 42}$.

2. En todo caso, con independencia de las oscilaciones en cuanto a la intensidad de la intervención que se exige en cada caso, puede decirse que en la práctica judicial ha ido configurándose un extenso catálogo de conductas que cumplirían con esta definición:

"Han sido acreditaciones consideradas suficientes para condenar por pertenencia-integración, tener por cometido la recepción y expedición de documentos explicativos de la organización terrorista; ser responsable de la ocultación, bajo tierra, de material preciso para la actuación de la organización, como croquis y datos sobre un polvorín; planos de la zona y datos de policías objetivos de atentados; poseer una máquina de escribir con la que se escribieron datos y señas de un empresario; tener pisos locales para cobijar a activistas; guardar armas y explosivos; aceptar estar encuadrado en un "talde" legal de la organización; tener conocimiento y disponibilidad de un buzón; participar en la construcción de un "zulo"; facilitar llaves de un piso de su propiedad; proporcionar el teléfono, filiación y contraseñas a la organización." ${ }^{43}$

Algunos años más tarde, la AN actualiza -y, como se verá, amplía- su catálogo, distinguiendo entre organizaciones: "Han sido actividades consideradas suficientes para condenar por pertenencia/integración en organización terrorista:

A) Con respecto a la organización terrorista ETA:

- tener por cometido la recepción y expedición de documentos explicativos de la organización; ser responsable de la ocultación, bajo tierra, de material preciso para la actuación de la organización, como croquis y datos sobre un polvorín, planos de la zona y datos de policías objetivos de atentados;

- poseer una máquina de escribir con la que se escribieron datos y señas de un empresario;

- tener pisos-locales para cobijar a activistas;

\footnotetext{
40 STS 15.4.1993.

41 STS 17.6.2002.

42 AAN (secc. $\left.4^{\mathrm{a}}\right)$ 8.2.2001.

43 SAN 28/2000 (secc. $4^{\mathrm{a}}$ ) 20.10.2000.
} 
Cancio - El delito de pertenencia a una organización terrorista...

- guardar armas y explosivos;

- aceptar estar encuadrado en un «talde» legal de la organización; tener conocimiento y disponibilidad de un buzón; participar en le construcción de un «zulo»;

- facilitar llaves de un piso de su propiedad; proporcionar el teléfono, filiación y contraseñas a la organización;

- etc.

B) Por lo que respecta a la integración en la organización terrorista $\mathrm{Al}$ Qaeda (vid. las ya citadas AN Secc 3a, S 36/05 de 26 septiembre y Secc. 4a, S 43/05 de 4 oct):

- Convencer a otros para realizar la Yihad; esto es, el adoctrinamiento en el fundamentalismo islámico (esto es, defensa a ultranza de los postulados religiosos, con su imposición por cualquier medio, para la definitiva instauración de un estado islámico).

- Enviar a alguien a campamentos de entrenamiento controlados por Al Qaeda, para que allí se adiestrasen en el manejo de armas y explosivos y en tácticas terroristas.

- Regresar a nuestro país después de haber estado en aquellos campamentos, debidamente adiestrados.

Poseer instrucciones precisas acerca de cómo fabricar explosivos, con elementos de fácil adquisición.

- Dar ayudas económicas para los anteriores fines." ${ }^{\$ 4}$

Esta es, como antes se decía, una prueba de indicios:

"...del relato fáctico se llega a la conclusión de que el recurrente se incorporó de forma efectiva a un comando de la organización armada "ETA", asumiendo labores de información y cooperación para los fines del grupo. Esta actividad se especifica de manera concreta y se le atribuye la preparación de un buzón para utilizarlo como medio de comunicación y una permanencia en la estructura del comando que le atribuye la vigilancia de los movimientos de otro miembro del comando sobre el que recaían sospechas de ser un infiltrado. Su actuación aparece vinculada a la organización y funcionamiento del comando con el que participa en diversas actividades de funcionamiento interno como en la llamada realizada para avisar de la colocación de un artefacto explosivo y para reivindicar su implantación" 45 .

En este sentido, se ha afirmado, como indicio de pertenencia, que ETA no encarga transporte de explosivos desde Francia a España a alguien que no sea de plena confianza, esto es, a un integrante de la organización ${ }^{46}$, o que la tenencia de

\footnotetext{
44 SAN (secc. $2^{a}$ ) 31.3.2006; en la sentencia se afirma la concurrencia de integración en un sujeto encargado de elaborar una página web para AlQaida.

45 STS 15.4.1993.

46 STS 1346/2001 (28.6.2001).
} 
diversos materiales, como explosivos y diversos elementos accesorios, así como de documentos falsos, también indica claramente la situación de integración ${ }^{47}$. Sin embargo, en otra resolución anterior se había estimado que aquello que en la sentencia acabada de citar es un indicio claro de pertenencia a banda armada, no pasa de describir, en realidad, una conducta constitutiva de colaboración:

“...la sentencia recurrida... recoge tres hechos básicos debidamente probados: a) El importantísimo material de armas y explosivos que ETA había confiado a los dos acusados. b) Los escondites que éstos tenían preparados para ocultar tales armas. c) Su forma coordinada de actuar, tanto en la recepción como en el transporte de tal material. Pero tales tres indicios, apreciados conjuntamente, son compatibles, tanto con la pertenencia a la banda ETA como con que simplemente le ayudaran sin encontrarse integrados en la misma. Partiendo de tales tres indicios bien pudo ocurrir que, sin formar parte de dicha organización, los dos acusados prestaron su auxilio desde fuera, como es frecuente, tal y como la experiencia de casos semejantes nos pone de manifiesto. Por ello entendemos que no es razonable deducir de estos tres indicios la consecuencia de que P. y F. se hallaban integrados en la banda ETA." 48

En última instancia, con independencia del acierto en la decisión concreta en cada caso, queda claro que lo que procede es una consideración funcional: podrá ser considerado miembro de una organización quien desarrolle las tareas que típicamente suelen quedar reservadas a los que pertenecen a ella. Como es obvio, hasta cierto punto será necesario conocer, entonces, las máximas organizativas del colectivo terrorista para poder marcar la frontera entre la pertenencia y la mera colaboración. Una vez conocida esta estructura de la organización, los concretos actos de intervención en la dinámica de la organización terrorista son imprescindibles como medios de prueba en cuanto son la única demostración posible del hecho de fondo que interesa, la integración en la organización, la puesta a disposición del sujeto para las funciones que la organización quiera atribuirle. Este modo de argumentación indirecto - del acto concreto a la inferencia de la pertenencia- se repite con regularidad en las sentencias que se ocupan de la cuestión:

"...desde 1988 el acusado facilitaba... información sobre policías y guardias civiles que podían ser objetivos de las acciones de ETA. Estos hechos... demuestran una relación temporalmente extendida y no meramente puntual, que junto con el cumplimiento regular de una función propia de los fines de la organización armada permite afirmar la pertenencia a la misma. Es claro que estos dos elementos son suficientes

\footnotetext{
47 STS $1127 / 2002$ (17.6.2002).

48 STS 563/1997 (25.4.1997), sin cursiva en el original.
} 
Cancio - El delito de pertenencia a una organización terrorista...

para demostrar una relación estabilizada y funcionalmente estructurada que revela la relación de pertenencia" ${ }^{, 9}$.

Sin embargo, con esa consideración funcional -¿qué actos son típicos de un miembro en esta organización?- no se pueden resolver todos los supuestos, teniendo en cuenta que existe en la práctica la posibilidad de amplios solapamientos, como antes se ha visto, entre conductas de colaboración y de pertenencia, es decir, comportamientos que pueden ser asumidos tanto por miembros como por colaboradores externos. En este ámbito, puede ser un indicio que ayude a distinguir ambas situaciones la duración temporal de la relación con la organización y la jerarquía de las personas con las que mantiene contacto ${ }^{50}$.

3. También deberá acudirse, finalmente, a una consideración funcional -en torno al funcionamiento real del colectivo en cuestión- para determinar quiénes son dentro de la organización "promotores, directivos o dirigentes de sus grupos" " Esta calificación puede corresponder, como es lógico, a sujetos muy alejados de la comisión efectiva de delitos instrumentales:

"El concepto de miembro de organización terrorista no puede quedar relegado a la persona que empuña armas o coloca bombas, sino que abarca a la totalidad de los que participan en la actividad finalísticamente terrorista en cualquiera de sus necesarias e indispensables facetas intermedias." 52

En efecto, lo que aquí cuenta es su posición en la estructura interna de la organización (y no si tiene las manos físicamente manchadas de sangre):

[el acusado] “...había sido responsable del aparato logística, ocupándose de las labores de formación y cursillos, encargándose de fijar las líneas ideológicas del grupo y en consecuencia de orientar los objetivos de las actuaciones de los comandos armados, y que a partir de ese año siguió actuando como órgano directivo al menos en materia orientación políticoideológica... deben considerarse los hechos constitutivos de un delito de pertenencia a banda armada, en su modalidad de órgano directivo... El que la sección de formación y cursillos se encuadre en el aparato de logística, y ésta en un comité ejecutivo, con una dirección colegiada, no excluye la aplicación de este tipo agravado, que se refiere tanto a promotores y directivos como a los dirigentes de cualquiera de los grupos. ${ }^{, 53}$

\footnotetext{
49 STS 17.3.1997.

50 Vid., por ejemplo, SAN (secc. 2a 31.3.2006 y STS 119/2007 (16.2.2007).

51 Cfr., por lo demás, el extenso análisis de GARCía-PABLos DE MolinA, Asociaciones ilícitas, pp. 248 y ss.

52 SAN 6/2007 (secc. 1 1) 7.2.2007.

53 SAN 15/2001 (secc. $\left.4^{a}\right)$ 17.4.2001.
} 
REJ - Revista de Estudios de la Justicia - No 12 - Año 2010

\section{Epílogo}

Dejando de lado la enorme severidad de las penas, que debería ser atemperada, cabe constatar que existe últimamente cierta tendencia en la jurisprudencia a definir la mera pertenencia a una organización terrorista como un delito formal, de mera adhesión a un ideario, cuando lo que debe hacerse por los tribunales es definir un concepto de conducta material de pertenencia claramente delimitado. Éste debe pasar por la idea de que el miembro se pone activamente a completa disposición de la organización. 
Cancio - El delito de pertenencia a una organización terrorista...

\section{BIBLIOGRAFÍA}

* Avilés Gómez, Manuel: Criminalidad organizada. Los movimientos terroristas, Editorial Club Universitario, Valencia, 2004, (cit.: AvILÉS GÓMEZ, Criminalidad organizada).

* Bustos Ramírez, Juan: Manual de Derecho penal, Parte Especial, Ariel, Barcelona, 1991, (cit.: Bustos Ramírez, PE).

"In-seguridad y lucha contra el terrorismo", en: LOSANO/MUÑOZ CONDE (coord.), El Derecho ante la globalización y el terrorismo. 'cedant arma togae'. Actas del Coloquio internacional Humboldt, Montevideo abril 2003, Tirant Lo Blanch, Valencia, 2004, (cit.: Bustos Ramírez, en: Losano/MuÑoz CONDE, El Derecho ante la globalización y el terrorismo).

* Cancio Meliá, Manuel: "Derecho penal del enemigo" y delitos de terrorismo. Algunas consideraciones sobre la regulación de las infracciones en materia de terrorismo en el Código penal español después de la LO 7/2000", en: JpD 44 (2002).

"De nuevo: ¿’Derecho penal' del enemigo?", en: Jakobs/CAnCio Meliá, Derecho penal del enemigo, $2^{a}$ ed., Civitas, Madrid, 2006, (cit.: CANCIO MELIÁ, en: JAKOBS/CANCIO MELIÁ, Derecho penal del enemigo).

"Zum Unrecht der kriminellen Vereinigung: Gefahr und Bedeutung", en: PAWLIK/ZACZYK (ed.) et al., Festschrift für Günther Jakobs zum 70. Geburtstag am 26. Juli 2007, 2007, (= "El injusto de los delitos de organización: peligro y significado", RGDP 8 [2007]).

"Sentido y límites de los delitos de terrorismo", en: GARCía VALDÉs et al. (ed.), Estudios Penales en homenaje a Enrique Gimbernat, tomo II, Edisofer, Madrid, 2008.

Los delitos de terrorismo: estructura típica e injusto, en prensa para ed. Reus, Madrid.

* Carbonell Mateu, Juan Carlos: “Observaciones en torno al proyecto de Ley sobre reforma del Código penal en relación a los delitos cometidos con ocasión del ejercicio de los derechos fundamentales y libertades públicas", en: Documentación Jurídica 37/40, Monográfico dedicado a la PANCP, vol. 2, 1983, (cit.: CARBONELl MATEU, DJ 37/40 (1983) vol. 2).

* García-Pablos de Molina, Antonio: Asociaciones ilícitas en el Código penal, Bosch, Barcelona, 1977, (cit.: GARCÍA-PABLOS DE MOLINA, Asociaciones ilicitas).

"Asociaciones ilícitas y terroristas", en: COBO DEL ROSAL (dir.)/BAJO FERNÁNDEZ (coord.) et al., Comentarios a la Legislación penal, t. II, El Derecho penal del Estado democrático, 1983, (cit.: García-Pablos de Molina, ComLP II).

* Hernández Hernández, Roberto, Comentario a los delitos de terrorismo, en: CondePuMPIDO FERREIRO (dir.), Código penal. Doctrina y jurisprudencia, t. III, art. 386 a disposiciones finales, Trivium, Madrid, 1997, (cit.: HERnÁNDEZ HERNÁNDEZ, CP-DyJ III).

* JAKOBS, Günther: "Kriminalisierung im Vorfeld einer Rechtsgutsverletzung”, en: ZStW 97 (1985).

Die staatliche Strafe: Bedeutung und Zweck, Academia de las Ciencias de Nordr- heinWestfallen, 2004 (cit.: JAKOBS, Die staatliche Strafe).

“Terroristen als Personen im Recht?", en: ZStW 117 (2005), (= en: JAKOBS/CANCIO MELIÁ, Derecho penal del enemigo, $2^{\mathrm{a}}$ ed., Civitas, Madrid, 2006).

"¿Derecho penal del enemigo? Un estudio acerca de los presupuestos de la juridicidad”, en: CANCio Meliá/Gómez-Jara DíEZ (coord.), Derecho penal del enemigo. El discurso penal de la exclusión, volumen 2, Edisofer, Madrid, 2006.

* KindHäUser, Urs: Strafgesetz̧buch. Lehr- und Praxiskommentar, $2^{\mathrm{a}}$ ed., Nomos, Baden-Baden, 2005, (cit.: KINDHÄUSER, LPK StGB2).

* Lamarca Pérez, Carmen: “Terrorismo", en: EAdem (coord.) et al., Derecho penal. Parte Especial, $3^{a}$ ed., Colex, Madrid, 2005, (cit.: LAMARCA PÉREZ, en: EADEM, PE³). 
REJ - Revista de Estudios de la Justicia - No 12 - Año 2010

* LANGER-STEIN, Rose: Legitimation und Interpretation der strafrecbtlichen Verbote krimineller und terroristischer Vereinigungen $\left(\$ \int 129,129\right.$ a StGB), VVF, München, 1987, (cit.: LANGER-STEIN, Legitimation und Interpretation).

* LuTZ, James M., y LuTZ, Brenda J: Global Terrorism, Routledge, Londres, 2004.

* Manjón-Cabeza Olmeda, Araceli: “Apología del terrorismo", en: Octavio de toledo y Ubieto/GuRdiel SiERrA/CORTÉs BECHIARELLI (coord.), Estudios penales en recuerdo del profesor Ruiz, Antón, Tirant lo Blanch, Valencia, 2004.

* Moral de la Rosa, Juan: Aspectos penales y criminológicos del terrorismo, Centro de Estudios Financieros, D. L., Madrid, 2005, (cit.: MORAL DE LA ROSA, Terrorismo).

* Portilla Contreras, Guillermo: "Delitos contra la Constitución (V). Delitos relativos al ejercicio de los derechos fundamentales y libertades públicas, y al deber del cumplimiento de la prestación social sustitutoria (II)", en: COBO DEL ROSAL (dir.) et al., Curso de Derecho penal español. Parte Especial, II, Dykinson, Madrid, 1997, (cit.: PORTILLA CONTRERAS, en: COBO DEL Rosal, Curso PE II).

* Roldán Barbero, Horacio: Los GRAPO. Un estudio criminológico, Editorial Comares, Granada, 2008.

* SÁNCHEZ García de PAZ, María Isabel: "Función político-criminal del delito de asociación para delinquir: desde el Derecho penal político hasta la lucha contra el crimen organizado", en: Arroyo Zapatero et al. (ed.)/Nieto MArtín (coord.), Homenaje al Dr. Marino Barbero Santos in memoriam, vol. II, Ediciones de la Universidad de Castilla la Mancha, Ediciones Universidad de Salamanca, Cuenca, 2001.

* Schroeder, Friedrich-Christian: Die Straftaten gegen das Strafrecht, Gruyter-Recht, Berlin, 1985.

* Silva SÁnchez, Jesús-María: “¿’Pertenencia' o 'intervención’? Del delito de 'pertenencia a una organización' a la figura de la 'participación a través de organización’ en el delito”,

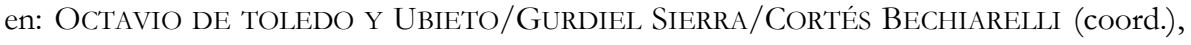
Estudios penales en recuerdo del profesor Ruiz. Antón, Tirant lo Blanch, Valencia, 2004.

* Terradillos Basoco, Juan: Terrorismo y Derecho. Comentario a las LL.OO. 3 y 4/1988, de reforma del Código Penal y de la Ley de Enjuiciamiento Criminal, Tecnos, Madrid, 1988, (cit.: TERRADIllos BASOCO, Terrorismo y Derecho).

Comentario a los arts. 174, 174 bis a) y 174 bis b), en: BARJA DE QUIROGA/RODRÍGUEZ Ramos (coord.), Código penal comentado, Akal, Madrid, 1990, (cit.: TeRRAdiLlos BASOcO, CPCom). 